\title{
The Development Measures of Circular Economy in Jilin Province
}

\author{
Juan Zhang \\ Economics and Management Institute, Department of Management \\ Changchun University of Science and Technology \\ Changchun 130022, China \\ E-mail: zhangjuan5791@163.com
}

\begin{abstract}
The development of circular economy is the strategic choice of Jilin Province to improve overall competitiveness. This article described specific measures of the development of circular economy in Jilin Province from five aspects as follows: the building of circular economy industrial park and business groups, the development of modern agriculture, improve the utilization of water resources, as well as the construction of laws and regulations.
\end{abstract}

Keywords: Jilin Province, Circular economy, Resources and ecological environment protection

Circular economy refers to the economic shape which characteristics are resource conservation and recycling. It is the economic development mode characterized "resources - products - renewable resources - products", showing the effect of low consumption, low pollution, high efficiency and high cycle rates on the environment and cutting down the impact of economic activities on the natural environment to the smallest possible level. The main features of circular economy are waste reduction, recycling and sound. The basic ways to develop recycling economy including the implementation of clean production, comprehensive utilization of resources, construction of ecological industrial park, to carry out renewable resources recycling, developing green industries and the promotion of green consumption and so on.

Jilin Province began to develop circular economy while building an ecological province. The province has 10 industrial parks which have been declared as the provincial eco-industrial park and organized and directed 23 units in construction of ecological demonstration, in which 10 pilots are state-level ecological demonstration zones. Jilin Province is relative lack of mineral resources and water, relatively rich in biological resources. Therefore, to explore ways to develop a recycling economy in order to reduce resource consumption and improve the comprehensive utilization rate is related to the long-term interests of the people of the province.

\section{Construction of the circular economy industrial park and business groups around key industries}

Based on the mode of circular economy within the enterprise, select a number of national and provincial level development zones in province-wide, such as high-tech development zone in Changchun, Jilin Economic Development Zone, Changchun Dacheng Biochemical Industrial Zone, (Dehui), as pilot of the establishment of eco-industrial Park. According to principles of eco-industrial and material supply and demand side requirements for ecological planning, to design and renovate, to implement restructuring of ecological and economic. Through the physical integration between enterprises, energy integration and information integration, to establish the closed circulatory system, metabolic waste exchange and industrial symbiosis system between enterprises and the whole park.

\subsection{Establishment of chemical recycling economy industrial park}

Jilin Province was once the national chemical industry base, proportion of the chemical industry in Jilin, Siping, Liaoyuan city is big, industrial parks should be set up to form chain chemical processing from raw material to fine chemical. It should be centralized control on chemical pollution and heavy metal pollution and on the chemical industry garbage and sewage treatment and disposal, with emphasis on chemical raw materials, heavy metals and water recycling loop. Otherwise, the focus should be the development of the chemical materials and chemical waste processing and recycling of small and medium groups.

\subsection{Establishment of automotive and equipment industry circular economy industrial park}

Jilin is the country's major automobile and equipment, industrial base, but they are in vehicles, machine-based production. With the development of the market economy, spare parts and related upstream and downstream industries will be supporting the development more substantial. Therefore, the establishment of circular economy 
industrial park to reduce infrastructure investment and to short the distance between the industrial chain, to low transaction costs of resources, to share markets, infrastructure and to be comprehensive and recycling utilization of raw materials, water resources and energy.

\subsection{Establishment of agricultural and livestock products in the cycle of economic zone}

Jilin Province is the largest commodity grain base, per capita consumption of grain and livestock products are the first in the nation, agricultural and livestock processing industry is developing rapidly. According to the practice of Jilin Province and the actual characteristics of agricultural and livestock products processing industry, too scattered layout of agricultural and livestock products should be adjusted ,to select the line along the Songhua River, Harbin's interchange with the establishment of radiation-based agricultural and livestock processing cycle economic zone ,to implement the integrated utilization of agricultural and livestock products and the concentration of pollution control on the agricultural products processing .

\section{Develop sustainable and modern intensive ecological agriculture}

Modern agriculture is ecology-based, modern agricultural technology is its means and its core is sustainable agricultural development to pursuit balance of agriculture, environment and ecology in order to achieve the ultimate goal of agricultural safety and human health. General principle is to make environmental protection compatible with economic development and the coordination of resource utilization and sustainable development .Development of eco-type of modern sustainable agriculture can improve the population carrying capacity, ensure food safety and human health. Based on the present northern adaptation of "Four in One" ecological model and supporting technology, to develop and establish agricultural recycling economy to suit different characteristics of, eastern, central and western ecological environments in Jilin Province. "Four in One" ecological model is on the conditions of the combination of natural control and manual control, and use renewable energy sources (biogas, solar) to protect cultivation (greenhouse vegetables), greenhouse pig (poultry) and toilets. Through the rational allocation to form energy flow and logistics healthy circulatory system which takes solar energy as residue, biogas slurry as fertilizer sources and combined the planting and breeding industries.

Complex ecological models of forestry and animal husbandry and supporting technology should be developed in the eastern part of Jilin province to. Complex ecological models of agriculture, forestry, animal husbandry and supporting technologies should be developed in the middle, such as "Grain and Feed - straw - swine and poultry - biogas - fertilizer" recycling mode. Complex ecological model and supporting technologies should be developed in the western pastoral, namely, planting and breeding industry mainly within the recycling mode, such as "grain, grass - animal - residue - fish feed - fish" recycling mode.

\section{Establishment of water-saving society to improve water use efficiency}

Jilin province is lack of water resources, water resources will become a restricted major factor in social and economic development of Jilin Province, and efforts to establish water-saving society become extremely important. The average water resources in Jilin province are only the $1.4 \%$ of national total, per capita water resources is $68 \%$ of national average and is moderate water shortage area. In recent years, the total water resources in Jilin province are gradually reduced. In 20 years, the average reduction of surface water area are 11,400 hectares .For 6 years, the province's average annual precipitation reduced are more than $60 \mathrm{~mm}, 112$ cubic meters of water resources reduced. Therefore, saving water, recycling of water resources is a big problem in the production and living. At present, the direct discharge of sewage into rivers of the whole cities and industrial and mining enterprises each year are 15 billion cubic meters, $80 \%$ of industrial wastewater discharged directly into surface water bodies. According to authorities predict, with industrialization and urbanization, the province's industrial water use will reach 6.1 billion cubic meters, $22 \%$ of the total water demand to 2030 year. If water reuse rate comes to $60 \%$, it can save water for industrial use nearly 10 billion cubic meters and to reach 3.7 billion cubic meters in 2030 year, which greatly enhance the urban population and economic carrying capacity.

Use of "water", that is through sewage treatment facilities, and meet the "miscellaneous water standard" of reclaimed water, is an important "renewable water resources." In addition to drinking, this water can be used for urban life "flushing", green water, wash water; water can also be used for less demanding quality industrial water. It reflects the use principle of water "low-quality low-use".

Water use is the main ways of environmental protection, pollution prevention and control, is an important part of the social and economic sustainable development. Laws and regulations should be established to perfect the "water reuse". Through the development and promulgation of "in water usage" or "Water Law" to support urban water reuse with a national force; To improve and reform the existing water price system to be a scientific and 
reasonable water price system, relying on price measures to promote the formation of the water use market, expanding market demand for water use, thus promoting water reuse of industrial development, to achieve the purpose of water conservation, to rationalize urban water sector management relations for urban water management system.

It is necessary to treat water resources as a strategic resource for sustainable development, to control water resources scientifically, to arrange rationally the surface water, groundwater, and water supply, water usage, to achieve a win-win of environmental and economic benefits; Formulate preferential policies to nurturing the water use market and to encourage the use of water. Take the water use of "market-oriented, industrial, enterprise, professional" as the target, and vigorously develop the market management bodies. Multinational water companies to actively participate in the introduction of city water use facilities, construction and operation, development and investment, consulting, research, supervision and other factors, to encourage and attract foreign investment in social capital and water reuse project construction and operation, implementation of the basic risk compensation fund construction methods and other means to ensure return on investment.

Increase capital investment of water reuse market, and the Government can give priority to certain environmental project loans to enterprise to construct water facilities on the self-financing, or give financial discounts. Reduce value-added tax, income tax and water tax capacity increase fees in water production enterprise. Relief municipal package fee of specific water use projects or free provision of land use rights. Reduce the unit water treatment fee for use discretion, water quality and quantity of fresh water should be guaranteed priority.

\section{Improve the re-utilization of various resources}

Renewable resources recycling and utilization is an important indicator of ecological civilization construction. Therefore, we must learn from the advanced experience of developed countries to establish appropriate requirements of national economic development and renewable resource recycling system.

A number of departments involved in the current management of renewable resource recycling in Jilin province and the industry based on poor management, operation disorder, and urgent need is to speed up the building of regulations and standards for renewable resource recycling and reuse, regulate and control the introduction of strong administrative regulations to strengthen sector management. Learn from experiences of developed countries and start to formulate such laws and regulations as green consumption, recycling use of resources; establish and improve various types of renewable resource recycling system, to make clear that the manufacturer is responsible for recycling industrial waste and product packaging, construction unit is responsible for recycling construction waste from the building, garbage collection by the government and the residents and units pay appropriate fee; develop polices and incentives of full use renewable resources, take part on the incentives of taxation and investment in renewable resources.

\subsection{Improve the technical level and management level of renewable resource industry}

On the one hand to introduce and absorb new foreign technology and new equipment, accelerating renewable resources, waste recycling of technology advancement and improving resource utilization; on the other hand, to develop related incentives for investment efforts to guide foreign investment to renewable resource industries and encourage foreign investment in China to set up processing centers of renewable resources.

\subsection{Give policy support to renewable resources recovery industry}

The current policy state for renewable resources, waste recycling enterprises to be exempt from value-added tax can only maintain the survival and can not solve the problem of the industry development. More support efforts should be made in the financial system and investment system in the process of increasing public finance for renewable resources, and necessary support should be given in corporate direct financing and credit.

\subsection{Specification renewable resources processing network}

Establish municipal recycling network according the principles to be convenience, health, standard, and orderly and sustainable development. And incorporated into national economic development program, overall planning of urban construction, and city commercial network planning, including the establishment of community recycling sites, set recovery, sorting, market transaction processing for the integrated market of renewable resources, comprehensive utilization of processing networks.

\subsection{Strengthen publicity and education efforts to raise people's awareness of resources recycling}

Include the knowledge of recycling of renewable resources into the primary and secondary education textbooks, so make the idea of circular economy in the next generation deep-seated; set up professional tutorials on 
renewable resources in colleges to train professional and technical personnel; strengthen the training of employees to improve the quality of employees; by organizing various forms of publicity and education activities to improve the social saving resources, environmental protection awareness, so that all sectors of society to understand, support and conscientious participation in the cause of renewable resource recycling and utilization.

\section{Establish and improve the law and regulations of circular economy}

Development of recycling economy and promote comprehensive utilization of resources is an important way to transform the economic growth, promote economic development, coordination of resources and the environment. To promote circulation through the development of sound economic development, comprehensive utilization of resources laws, regulations, and gradually achieves economic development and resource and environment of the target, full use should be made of newspapers, radio, television, internet and promotional tools and mass media, extensively publicity to promote circular economy, promote clean production, improve the important role of resource utilization on the population development in the formation of the whole society to develop a recycling economy and to improve the survival environment.

\section{References}

Fu, Shipping. (2005). Introduction of harmonious society. Beijing: People's Publishing House.

I. Jiangsu. (2004). Research on the theory of circular economy and policy thinking. New Vision.

Mao, Rubai \& Ma, Zhijun. (2003). The research on the circular economy. Beijing: Economic Science Press.

Statistics Bureau. (2005). Jilin Statistical Yearbook Editorial. Changchun: Yearbook Club, 464-481. 